\title{
PERBANDINGAN PENGGUNAAN METODE COLLABORATIVE LEARNING DAN DISCOVERY LEARNING TERHADAP HASIL BELAJAR SISWA KELAS VII SMP DARUL ARAFAH
}

\author{
Ira Vahlia \\ Pendidikan Matematika FKIP Universitas Muhammadiyah Metro \\ E-mail: iravahlia768@yahoo.co.id
}

\begin{abstract}
The aim of this research to analyze the essence of Junior high student learning outcomes Darul Arafah is still relatively low it is seen that the value of the student learning outcomes that achieve minimum completeness criteria (KKM) is still much below the passing standard, so it is still far from what is expected. From the analysis it can be concluded as follows: 1) There is a noticeable difference the average student learning outcomes are taught using methods of collaborative learning with an average of the learning outcomes of students who are taught with methods of discovery learning on the subject of integers students in grade 7 SMP Darul Arafah Sukajawa the school 2015/2016. 2) The average results learning collaborative learning method is lower than the average student learning outcomes are taught using methods of discovery learning on the subject of integers grade students grade 7 SMP Darul Arafah Sukajawa the school 2015/2016.
\end{abstract}

Keywords : collaborative learning, discovery learning method, study result,

\section{PENDAHULUAN}

Guru sebagai pelaksana pembelajaran yang berhubungan dengan peserta didik mempunyai peranan penting dalam usaha peningkatan mutu pendidikan. Untuk meningkatkan mutu pendidikan ini, maka diperlukan pemilihan metode mengajar yang cocok dengan materi pelajaran yang akan diajarkan. Guru melakukan pemilihan metode mengajar karena masing-masing mempunyai kelebihan dan kekurangan. Tujuan pemilihan metode mengajar ini adalah untuk mengefektifkan proses belajar mengajar guna meningkatkan daya serap siswa terhadap materi pelajaran tersebut, karena dari kenyataan yang ditemui, bahwa apa yang dicapai masih jauh dari apa yang diharapkan. Kenyataan yang ditemui bahwa hasil belajar belajar siswa rata-rata adalah rendah. Peneliti melakukan wawancara dengan guru SMP Darul Arafah Sukajawa tentang hasil belajar siswa dengan nilai Kriteria Ketuntasan Minimum (KKM) adalah 6,0 dan diperoleh data sebagai berikut: 
ISSN 2442-5419 Vol. 4, No. 2 (2015) 53-60

Tabel 1. Data hasil prasurvey ulangan harian kelas 7A SMP Darul Arafah

\begin{tabular}{|c|c|c|c|c|}
\hline No. & Nilai & Kriteria & Jumlah & \% \\
\hline 1 & $<6,5$ & Tidak Tuntas & 25 & 83 \\
\hline 2 & $\geq 6,5$ & Tuntas & 5 & 17 \\
\hline & Jumlah & & 30 & $100 \%$ \\
\hline
\end{tabular}

Dari data di atas dapat dilihat bahwa hasil belajar siswa masih relatif rendah hal ini terlihat dari siswa yang nilai hasil belajarnya yang mencapai Kriteria Ketuntasan Minimum (KKM) masih sebanyak 25 siswa atau $83 \%$ dari 30 siswa, hal ini masih jauh dari apa yang diharapkan.

Metode mengajar dalam pendidikan matematika merupakan bagian yang penting dalam proses belajar mengajar untuk mencapai keberhasilan di sekolah. Tetapi dalam kenyataannya masih banyak guru dalam melaksanakan program pengajaran matematika kurang memperhatikan penekanan dalam metode mengajarnya, sehingga masih banyak di sana sini kita dapatkan hasil belajar matematika belum dapat diwujudkan dan sesuai dengan yang diharapkan dan masih rendah oleh karena itu perlu adanya perhatian dan suatu peningkatan.

Dalam rangka peningkatan kualitas sama dalam melaksanakan proses belajar mengajar, maka diperlukan penekanan bagi setiap guru bidang studi dalam mengajar hendaknya dapat memilih metode pengajaran yang sesuai dengan bahan kajian yang akan diajarkan dan dipelajari oleh siswa. Karena penerapan metode yang tidak sesuai dengan topik pembahasan akan menjadi masalah dan menghambat bagi guru maupun siswa yang belajar.

Menurut Marjan dan Seyed (2012) Collaborative Learning adalah sebuah metode dalam pendidikan untuk mengajar dan belajar yang melibatkan kelompok peserta didik bekerja sama untuk memecahkan suatu masalah, menyelesaikan tugas, atau membuat suatu produk. Metode pembelajaran yang dilakukan dengan cara kerjasama yang dikembangkan guru dengan siswanya tidak sebatas dalam menyelesaikan berbagai persoalan dalam bahan ajar, tapi juga dalam menentukan pokok bahasan, strategi, dan alat.

Hamdani (2010:

menyatakan bahwa "Discovery (penemuan) adalah proses mental peserta didik mengasimilasikan suatu konsep atau suatu prinsip. Adapun proses mental, misalnya mengamati, menjelaskan, mengelompokkan, membuat kesimpulan, dan sebagainya." Jadi peserta didik menemukan suatu konsep pembelajaran dengan proses mengkontruksi sendiri, dengan bantuan guru. Pembelajaran Discovery Learning yang akan peneliti laksanakan di mana dalam proses 
pembelajarannya diciptakan lingkungan sosial yang kondusif untuk terlaksananya interaksi yang memadukan segenap kemauan dan kemampuan belajar peserta didik. Lingkungan yang dibentuk berupa kelompok-kelompok kecil yang terdiri dari empat atau lima peserta didik pada setiap kelas dengan anggota-anggota kelompok yang sedapat mungkin tidak bersifat homogen. Artinya, anggota-anggota suatu kelompok diupayakan terdiri dari peserta didik laki-laki dan perempuan, peserta didik yang relatif aktif dan yang kurang aktif, peserta didik yang relatif pintar dan yang kurang pintar. Dengan komposisi sedemikian itu dapat diharapkan terlaksananya peran tutor beserta tutee antarteman dalam setiap kelompok.

\section{METODE PENELITIAN}

Metode penelitian yang digunakan dalam penelitian ini adalah metode penelitian eksperimen. Dalam penelitian ini bersifat kuantitatif, bertujuan untuk meningkatkan hasil belajar matematika peserta didik. Pada penelitian ini jenis penelitian yang akan dilakukan adalah perbandingan, dimana peneliti menggunakan dua metode dalam pembelajarannya. Adapun dalam proses pelaksanaanya dibagi menjadi 2 kelompok yang terdiri dari 2 kelas, dan masing-masing kelas akan menggunakan metode yang berlainan, kelompok I menggunakan metode collaborative learning dan kelompok II menggunakan metode discovery learning.

\section{HASIL DAN PEMBAHASAN}

1. Uji kesamaan dua rata-rata

a. Rumus hipotesis

$\mathrm{H}_{0}: \mu_{1}=\mu_{2}$ (rata-rata hasil belajar siswa yang diajar menggunakan metode Collaborative Learning sama dengan rata-rata hasil belajar siswa yang diajar dengan metode Discovery Learning)

Ha : $\mu_{1}=\mu_{2} \quad$ (rata-rata hasil belajar siswa yang diajar menggunakan metode

Collaborative Learning tidak sama dengan rata-rata hasil belajar siswa yang diajar dengan metode Discovery Learning)

b. Rumus statistik yang digunakan

$$
\begin{aligned}
& t_{h i t}=\frac{x_{1}-x_{2}}{S g \sqrt{1 / n_{1}+1 / n_{2}}} \\
& S g^{2}{ }_{\text {hit }}=\frac{\left(n_{1}-1\right) S_{1}^{2}+\left(n_{2}-1\right) S_{2}^{2}}{n_{1}+n_{2}-2} \\
&=\frac{(40-1) 0,92906+(40-1) 1,09779}{40+40-2} \\
&=\frac{35,9034+42,8138}{78} \\
&=1,009195 \\
&=\sqrt{1,009195} \\
&=1,0046 \\
&=1,01(\text { pembulatan }) \\
& t_{h i t}=\frac{x_{1}-x_{2}}{S g \sqrt{1 / 40+1 / 40)}}
\end{aligned}
$$


ISSN 2442-5419 Vol. 4, No. 2 (2015) 53-60

$$
\begin{aligned}
& =\frac{5,1-6}{1,01 \sqrt{1 / 40+1 / 40}} \\
& =\frac{-0,9}{1,01 \sqrt{0,05}} \\
& =\frac{-0,9}{0,2258} \\
& =-3,9858 \\
& =-3,99 \text { (pembulatan) }
\end{aligned}
$$

c. Kriteria uji: Terima Ho jika

$$
-t_{1}-1 / 2 \alpha<t_{\text {hit }}<t_{1}-1 / 2 \alpha
$$

Dengan $\mathrm{dk}=n_{1}+n_{2}-2$

Pada taraf signifikasi 5\%

$$
\begin{aligned}
(\alpha= & 0,05) \\
t_{d a f} & =t_{\left(1-\frac{1}{2} \alpha\right)(n 1+n 2-2)} \\
& =t_{\left(1-\frac{1}{20.0 .5}\right)(40+40-2)} \\
& =t_{(0,975)(78)} \\
& =2,00
\end{aligned}
$$

Pada taraf signifikasi $1 \%$ (

$$
\begin{aligned}
& \alpha=0,01) \\
& t_{d a f}=t_{(1-1 / 2 \alpha)(n 1+n 2-2)} \\
& =t_{\left(1-\frac{1}{20.0 .01)}(40+40-2)\right.} \\
& =t_{(0,995)(78)} \\
& =2,66
\end{aligned}
$$

Dari perhitungan diatas terlihat bahwa baik pada taraf signifikasi $5 \%$ maupun $1 \%$ menunjukkan bahwa $t_{\text {hit }}<-t_{\text {daf }}$, dengan demikian tolak Ho yang berarti terima Hi dengan kata lain ada perbedaan rata-rata hasil belajar siswa yang diajar dengan menggunaan metode collaborative learning dengan metode discovery learning.
2. Uji Perbedaan dua rata-rata

a. Rumusan Hipotesis Ho : $\mu 1 \leq \mu 2$ ( rata-rata hasil belajar siswa yang diajar dengan metode Collaborative Learning lebih rendah atau sama dengan yang diajar dengan menggunakan metode Cooperative Learning Ho : $\mu 1>\mu 2$ ( rata-rata hasil belajar siswa yang diajar dengan metode Collaborative Learning lebih besar dari rata-rata hasil belajar ang diajar dengan menggunakan metode Cooperative Learning

b. Rumus statistik yang digunakan

$$
\begin{aligned}
t_{h i t}= & \frac{x_{1}-x_{2}}{S g \sqrt{1 / n_{1}+1 / n_{2}}} \\
= & \frac{40+40-2}{(40-1) 0,92906+(40-1) 1,09779} \\
= & \frac{35,9034+42,8138}{78} \\
= & 1,009195 \\
S g & =\sqrt{1,009195} \\
& =1,0046 \\
t_{h i t} & =\frac{x_{1}-x_{2}}{S g \sqrt{1 / n_{1}+1 / n_{2}}} \\
& =\frac{5,1-6}{1,01 \sqrt{(1 / 40+1 / 40)}} \\
& =\frac{-0,9}{1,01 \sqrt{0,05}} \\
& =-3,99 \text { (pembulatan) } \\
\text { c. } \quad & \text { Kriteria Uji : terima } \\
T_{h i t}< & t_{1-\alpha}
\end{aligned}
$$


Dengan $\mathrm{dk}=\mathrm{n} 1+\mathrm{n} 2-2$ Pada taraf signifikasi 5\%

$$
\begin{aligned}
(\alpha= & 0,05) \\
T_{d a f} & =t_{(1-\alpha)(n 1+n 2-2)} \\
& =t_{(1-0,05)(40+40-2)} \\
& =t_{(0,95)(78)} \\
& =1,67
\end{aligned}
$$

Dari perhitungan terlihat bahwa pada taraf signifikasi 5\% menunjukkan bahwa $t_{\text {hit }}<$ dari $t_{d a f}$, dengan demikian kesimpulan yang diperoleh adalah terima Ho dan tolak Hi yang berarti rata-rata hasil belajar siswa yang diajar dengan menggunakan metode Collaborative Learning lebih rendah dari pada rata-rata hasil belajar siswa yang diajar dengan menggunakan metode Discovery learning pada pokok bahasan bilangan bulat.

Berdasarkan kesimpulan analisis diatas, ternyata terdapat perbedaan hasil belajar matematika siswa, dan hasil belajar yang diperoleh utuk siswa yang diajar menggunakan metode Collaborative Learning lebih tinggi dari pada siswa yang diajar menggunakan metode Discovery Learning.

Secara teoritis, perbedaan tersebut didasarkan pada perbedaan tanggapan yang dilakukan oleh siswa selama mereka mengalami pengajaran dengan metode Collaborative Learning dan metode Discovery Learning. Tanggapan yang diberikan oleh siswa yang diajar dengan metode Discovery Learning, lebih aktif karena siswa ikut berpartisipasi langsung dalam proses pembelajaran yang sesuai dengan topik pokok bahasan yang diajarkan yaitu bilangan bulat dimana dalam pelaksanaanya siswa terdiri dari kelompok-kelompok kecil yang terdiri dasri 3 - 4 orang yang diusahakan aktif dalam proses pembelajaran tersebut dan bersifat heterogen dimana dalam kelompok tersebut dibentuk dari latar belakang yang berbeda-beda, baik siswa yang memiliki kemampuan akademis tinggi dengan siswa yang kemampuan akademisnya sedang atau rendah.

Guru sebelum proses pembelajaran Discovery Learning dilaksanakan telah menyiapkan alat bantu berupa Lembar Kerja Siswa (LKS) yang didalamnya telah terdapat gambaran-gambaran tentang materi yang akan dipelajari, sehingga siswa dalam proses pembelajaran Discovery Learning tidak mengalami kendala yang begitu berarti tentang materi yang akan dibahas dalam masing-masing kelompok tersebut. Dan di dalam proses ini guru hanya sebagai penengah dalam berlangsungnya proses tersebut.

Dengan demikian kesan yang dialami oleh siswa lebih mendalam dan tertanam dalam ingatan yang pada akhirnya berdampak pada peningkatan siswa tersebut dalam penguasaan materi yang diajarkan melalui pembelajaran dengan menggunakan metode Discovery 
Learning Akanmu (2013). Namun adapun kendala atau kelemahan dalam pembelajaran ini adalah periode waktu yang digunakan untuk membahas materi hingga mereka dapat menyelesaikan masalah yang disajikan itu cukup panjang, kemudian dalam pengamatan peneliti bahwa didalam sebuah kelompok seringkali didapat terlalu banyak alternative atau saran perbaikan yang membingungkan kelompok tersebut.

Didalam proses akhir yang dilakukan peneliti dalam proses pembelajaran tersebut yaitu penilaian, dimana dalam pembelajaran Discovery Learning ini dilakukan tes atau kuis yang dilakukan secara kelompok maupun individu. Tes individu nantinya akan memberikan informasi kemampuan setiap siswa dalam kelompok, sedangkan tes kelompok adalah hasil akhir kemampuan siswa dalam penggabungan dalam proses pembelajaran tersebut. Berdasarkan hasil penelitian Abdelrahman (2014) bahwa Discovery Learning dapat meningkatkan hasil belajar siswa karena merupakan metode yang tepat agar siswa dapat menemukan sendiri konsep materinya.

Soal yang diberikan berkaitan dengan materi yang menjadi topik yaitu bilangan bulat yang terdiri dari 5 soal essay yang sebelumnya oleh peneliti telah diklasifikasikan antara soal yang mudah, hingga yang sulit, yang kemudian dikerjakan siswa dengan batas waktu tertentu yaitu kurang lebih 45 menit atau satu jam pelajaran dan kemudian dilanjutkan mengoreksi jawaban secara bersama-sama dan setelah itu dilakukan proses penilaian dan pemberian rewards/ penghargaan kepada siswa yang memiliki nilai tertinggi.

Adapun pembelajaran dengan menggunakan metode Collaborative Learning, siswa merasa dirinya terbebani dengan kontinuitas tugas yang terasa memberatkan dan membuat mereka jenuh karena selalu diberikan beban tugas yang relative sama yaitu penyelesaian soal-soal. Pengajaran dengan menggunakan metode Collaborative Learning dimana guru menjelaskan materi secara umum, dan khusus dalam peneitian ini peneliti mengambil materi bilangan bulat sebagai materi ajar dengan cara menjelaskan terlebih dahulu didepan kelas cara menentukan konsep bilangan bulat. Penyajian informasi secara lisan yang dilakukan guru dalam metode ini dapat disebut ceramah.

Penyajian ceramah yang bersifat formal dan biasanya berlangsung selama 30 menit, kemudian mengajukan pertanyaan kepada siswa jika ada hal yang tidak dimengerti, kemudian langkah selajutnya guru memberikan contoh soal aplikasi dari konsep yang berkaitan dengan 
maateri, yang kemudian dilanjutkan dengan meminta siswa untuk mengerjakan jawaban dari contoh tersebut dipapan tulis atau mejanya dimana soal yang diajukan tersebut dapat dikerjakan dengan cara individu atau kelompok. Dan memberikan kesempatan kepada siswa untuk menanyakan hal-hal yang kurang dimengerti mengenai persoalan tersebut dan kegiatan yang terakhir adalah siswa mencatat materi pelajaran yang telah diberikan dan dilengkapi dengan pekerjaan rumah.

Adapun kekurangan dan kelemahan dari pembelajaran ini yang peneliti temukan bahwa terdapat faktor lain disamping hal yang telah dijelaskan diatas tentang proses pembelajaran Collaborative Learning yaitu mereka belum mempunyai pengalaman dan pengetahuan yang baik, sehingga kualitas atau target penyelesaian tugas-tugas yang dibebankan juga kurang optimal. Sehingga saya simpulkan bahwa apabila guru menggunakan metode Collaborative Learning maka siswa akan merasa jenuh dan terbebani oleh tugas-tugas yang diberikan oleh guru yang sifatnya monoton atau terus-menerus, sehingga perlu adanya metode yang lain dan tepat untuk meningkatkan hasil belajar siswa khusunya pada materi bilangan bulat.

\section{KESIMPULAN DAN SARAN}

Dari hasil analisis data penelitian ini, diperoleh kesimpulan sebagai berikut:

1. Ada perbedaan rata-rata hasil belajar siswa yang diajar menggunakan metode Collaborative Learning dengan rata-rata hasil belajar siswa yang diajar dengan metode Discovery Learning pada pokok bahasan bilangan bulat siswa kelas 7A SMP Darul Arafah Sukajawa Tahun Pelajaran 2015/2016.

2. Rata-rata hasil belajar siswa yang diajar menggunakan metode Discovery Learning lebih tinggi dari rata-rata hasil belajar siswa yang diajar dengan menggunakan metode Collaborative Learning pada pokok bahasan bilangan bulat siswa kelas 7A SMP Darul Arafah Sukajawa Tahun Pelajaran 2015/2016. Hasil penelitian ini sama sengan penelitian yang dilakukan oleh Rahayu (2014) bahwa Discovery Learning sangat baik diterapkan pada siswa SMP.

3. Penggunaan Metode yang tepat dalam proses belajar mengajar sangat berpengaruh terhadap hasil belajar siswa dalam materi bilangan bulat.

Berdasarkan kesimpulan penelitian di atas, diajukan beberapa saran yaitu: 
1. Pembelajaran dengan metode

Performance in Collaborative Learning dapat Mathematics $\quad .12 \quad$ (4): diimplementasikan untuk 213-215. Diunduh dari pengembangan pembelajaran sehingga dapat meningkatkan hasil belajar matematika.

2. Bagi peserta didik untuk membiasakan belajar dan bekerja sama dengan peserta didik lain untuk menambah informasi yang maksimal agar mendapat hasil belajar yang memuaskan.

\section{DAFTAR PUSTAKA}

Abdelrahman. 2014. International Journal of Innovation and Scientific Research. Sydney. The Effect of Using Discovery Learning Strategy in Teaching Grammatical Rules to first year General Secondary Student on Developing Their Achievement and Metacognitive Skills. 5(2): 146-153. Diunduh dari http://www.ijisr.issr-journals .org/ pada 10 Agustus 2015 pukul 09.00.

Akanmu, M, A. 2013.Journal of Education and Practice. Nigeria. Guided-discovery Learning Strategy and Senior School Students https://www.unilorin.edu.n g/publications/akanmuma/ pada 01 Agustus 2015 pukul 11.00.

Hamdani. 2010. Strategi Belajar Mengajar. Bandung: Pustaka Setia.

Marjan, L., dan Seyed, M, G. 2012. Benefits of Collaborative Learning. Iran. Jounal of Procedia - Social and Behavioral Sciences.31(2): 486 - 490. Diunduh dari http://www.science.com/sci ence/article/pii/S18770428 11030205 pada 15 Agustus 2015 pukul 10.30 .

Rahayu, P. 2014. Eksperimentasi Model Problem Based Learning dan Discovery Learning Pada Materi Perbandingan Dan Skala Ditinjau Dari Sikap Peserta Didik Terhadap Matematika Kelas Vii SMP Kabupaten Klaten Tahun Pelajaran 2013/2014. Tesis S2. Tidak Dipublikasikan. UNS Pascasarjana Surakarta. 